\title{
Synthesis of a Formyl Group-Containing Reactive Novolac
}

\author{
By Tadamasa NEMOTO, Isamu AMIR, and Gen-ichi KONISHI*
}

We report the preparation of a new novolac having formyl groups by the addition-condensation of 2,4,6-trimethoxybenzaldehyde (1) and 1,3,5-trimethoxybenzene (2) with formaldehyde. In the case of the polymerization of 1 and formaldehyde, polymerization did not occur; however, the polymerization of $\mathbf{1}, \mathbf{2}$ and formaldehyde proceeded to give polymer $3\left(M_{\mathrm{n}} 4200, M_{\mathrm{w}} / M_{\mathrm{n}} 1.2\right)$. The FT-IR, ${ }^{1} \mathrm{H}$ NMR and ${ }^{13} \mathrm{C}$ NMR spectra of $\mathbf{3}$ showed that it had phenylene-methylene units on the polymer backbone and the formyl groups of 1 remained without side reactions. To evaluate its ability as a reactive polymer, the imination of $\mathbf{3}$ with 1,5-diaminopentane was carried out to obtain an organo-insoluble gel (5), which had the network structure of $\mathbf{3}$ and a pentamethylene unit via the imine moiety. The temperature at $5 \%$ loss in weight $\left(T_{\mathrm{d} 5}\right.$, $\left.335^{\circ} \mathrm{C}\right)$ of $\mathbf{5}$ slightly decreased compared to that of $\mathbf{3}\left(351^{\circ} \mathrm{C}\right)$. This result indicates that polymer $\mathbf{3}$ can be utilized as a reactive polymer, and form a thermostable gel via the imine moiety.

KEY WORDS: Novolac / Phenolic Resin / Addition-Condensation / Reactive Polymer / Formyl Group / Imination / Gelation /

Phenolic resins (novolacs) ${ }^{1,2}$ have been used industrially as well as cures, adhesives, photoresists, and ion-exchange resins, etc. ${ }^{3,4}$ In particular, ion-exchange phenolic resins, ${ }^{3}$ those which were synthesized for the first time in $1935,{ }^{5}$ are one of the valuable synthetic reactive polymers, ${ }^{6-9}$ and the phenolic hydroxyl group of these resins plays an important role as a reactive polymer in the field of materials science. From this viewpoint, phenolic resins are often utilized as curing agents for epoxy resins ${ }^{10}$ furthermore, phenolic resins have a rigid rod-like poly(phenylenemethylene) backbone that exhibits characteristic properties, such as heat resistance and improved mechanical properties; ${ }^{11}$ accordingly materials cured by phenolic resins show high thermal stability and strength. However, their hydroxyl groups reduce the solubility of high-molecularweight phenolic resins. Recently, we reported alkoxylated novolacs ${ }^{12}$ which achieved high molecular weights as well as higher thermal stability and good solubility in chloroform, THF, toluene, etc. It is very important to extend the alkoxylated novolac to reactive polymers with high thermal stability and good processability.

In this study, the addition-condensation of 2,4,6-trimethoxybenzaldehyde (1) as a functional monomer and 1,3,5-trimethoxybenzene (2) with formaldehyde was carried out. To evaluate the potential of the obtained polymer $\mathbf{3}$ for use as a reactive polymer, the imination of $\mathbf{3}$ with hexylamine (to give the polymer (4)) or 1,5-diaminopentane (to give the polymer (5)) was carried out. Imine moieties are known as reversible formations, which can reversibly change from an imine formation to an amine/ketone moiety depending on the external environment through dynamic covalent chemistry. ${ }^{13}$ It is assumed that polymer $\mathbf{3}$ can be cured using a diamine to obtain an insoluble gel from imine moieties; however, the gel can be converted back to $\mathbf{3}$ by external stimuli. The thermal properties of the obtained polymers are also examined by thermogravimetric analysis (TGA).

\section{EXPERIMENTAL}

\section{Materials}

Unless otherwise noted, all reagents and chemicals were purchased from Wako Pure Chem., and used without further purifications. Paraformaldehyde (95\%) was obtained from Nacalai Tesque.

\section{Instruments}

All the ${ }^{1} \mathrm{H}$ NMR and ${ }^{13} \mathrm{C}$ NMR spectra were obtained in $\mathrm{CDCl}_{3}$ and recorded by using a JEOL LNM-EX 400 instrument with tetramethylsilane (TMS) as the internal standard. The Fourier transfer infrared (FT-IR) spectra were recorded by a JASCO FT-IR 460 plus spectrometer. Gel permeation chromatography (GPC) was performed either by a JASCO UV2075 detector and a JASCO RI-2031 detector (TOSOH TSKgel $\mathrm{G} 3000 \mathrm{H}_{\mathrm{XL}}$ or $\mathrm{G} 4000 \mathrm{H}_{\mathrm{XL}}$ column) using tetrahydrofuran (THF) as the eluent after calibration with polystyrene standards. Thermogravimetric analysis (TGA) was performed using a SII TG/DTA 6200 machine with a heating rate of $10^{\circ} \mathrm{C} / \mathrm{min}$ in a nitrogen atmosphere.

Addition-Condensation of 2,4,6-Trimethoxybenzaldehyde (1) with Formaldehyde. 2,4,6-Trimethoxybenzaldehyde (1, 1.96 $\mathrm{g}, 10 \mathrm{mmol})$ and paraformaldehyde $(0.30 \mathrm{~g}, 10 \mathrm{mmol}$ as a formaldehyde unit) and THF $(20 \mathrm{~mL})$ were added to a $50 \mathrm{~mL}$ round-bottom flask. After stirring for a while, to this mixture was added $12 \mathrm{~mol} / \mathrm{L} \mathrm{HCl}$ aq. $(2.0 \mathrm{~mL})$ at $0{ }^{\circ} \mathrm{C}$. After this mixture was stirred at $50^{\circ} \mathrm{C}$ for $12 \mathrm{~h}$, it was poured into excess amount of methanol to give no product.

Addition-condensation of 2,4,6-Trimethoxybenzaldehyde (1) and 1,3,5-Trimethoxybenzene (2) with Formaldehyde. 2,4,6Trimethoxybenzaldehyde $(0.98 \mathrm{~g}, 5.0 \mathrm{mmol})$, 1,3,5-trimethoxybenzene $(0.84 \mathrm{~g}, 5.0 \mathrm{mmol})$ and paraformaldehyde $(0.30$ $\mathrm{g}, 10 \mathrm{mmol}$ as a formaldehyde unit) and THF $(20 \mathrm{~mL})$ were

Department of Organic \& Polymeric Materials, Graduate School of Science \& Engineering, Tokyo Institute of Technology, SORST, Japan Science \& Technology Agency (JST), 2-12-1-H-134, Ookayama, Meguro-ku, Tokyo 152-8552, Japan

*To whom correspondence should be addressed (Tel: +81-3-5734-2321, Fax: +81-3-5734-2888, E-mail: konishi.g.aa@m.titech.ac.jp). 


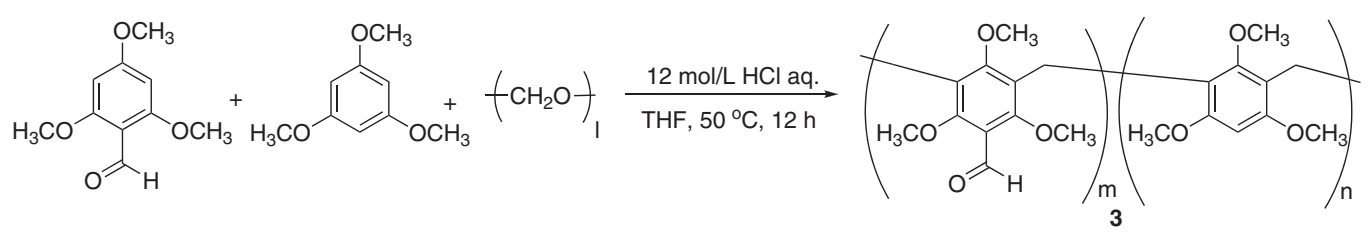

Scheme 1. Addition-condensation of 1 and 2 with formaldehyde.

added to a $50 \mathrm{~mL}$ round-bottom flask. After stirring for a few min, $12 \mathrm{~mol} / \mathrm{L} \mathrm{HCl}$ aq. $(2.0 \mathrm{~mL})$ was added at $0{ }^{\circ} \mathrm{C}$. After this mixture was stirred with a reflux condenser at $50^{\circ} \mathrm{C}$ for $12 \mathrm{~h}$, it was poured into methanol to obtain the crude product. The residue was reprecipitated with $\mathrm{THF} /$ methanol three times to give the objective product (3) as a light blue precipitate in $9 \%$ yield. ${ }^{1} \mathrm{H} \mathrm{NMR}\left(\mathrm{CDCl}_{3}, 400 \mathrm{MHz}, \delta, \mathrm{ppm}\right): 2.95-3.80$ $\left(\mathrm{Ar}-\mathrm{OCH}_{3}\right), \quad 3.80-4.40$ (Ar- $\left.\mathrm{CH}_{2}-\mathrm{Ar}\right)$, 5.90-6.25 ( $\left.\mathrm{Ar}-\mathrm{H}\right)$, 10.14-10.30 (Ar-CHO); ${ }^{13} \mathrm{C} \mathrm{NMR}\left(\mathrm{CDCl}_{3}, 100 \mathrm{MHz}, \delta\right.$, ppm): 17.0-21.0 (Ar- $\left.\mathrm{CH}_{2}-\mathrm{Ar}\right), 54.0-64.0\left(\mathrm{Ar}-\mathrm{OCH}_{3}\right), 90.0-$ 94.0 (aromatic $C-\mathrm{H}$ ), 114.0-118.0, 122.0-126.0 (aromatic $C-\mathrm{CH}_{2}$ ), $\quad 155.0-160.0, \quad 161.0-165.0$ (aromatic $C-\mathrm{OCH}_{3}$ ), 187.0-189.0 (Ar-CHO).; FT-IR ( $\left.\mathrm{KBr}, \mathrm{cm}^{-1}\right)$ : 2939, 2833 $\left(-\mathrm{CH}_{2}-\right), 1678(\mathrm{CHO}), 1593$ (aromatic $\left.\mathrm{C}=\mathrm{C}\right), 1107$ (Ar-O$\mathrm{CH}_{3}$ ).

Imination of Polymer $\mathbf{3}$ with Hexylamine. ${ }^{14}$ Polymer $\mathbf{3}$ $(0.081 \mathrm{~g}, \quad 0.10 \mathrm{mmol}$ as an aldehyde unit estimated by ${ }^{1} \mathrm{H}$ NMR spectrum) and hexylamine $(3.4 \mathrm{~g}, 34 \mathrm{mmol})$ solution of ethanol $(10 \mathrm{~mL})$ were added to a $50 \mathrm{~mL}$ round-bottom flask. After the mixture was stirred at $40{ }^{\circ} \mathrm{C}$ for $30 \mathrm{~min}$, it was cooled inside the refrigerator. Dichloromethane $(50 \mathrm{~mL})$ was added to the reaction solution, and then the mixture was washed several times by $1.2 \mathrm{~mol} / \mathrm{L} \mathrm{HCl}$ aq. $(100 \mathrm{~mL})$ and brine. The organic layer was dried over $\mathrm{Na}_{2} \mathrm{SO}_{4}$ and evaporated to $5 \mathrm{~mL}$. The resulting solution was poured into hexane $(50 \mathrm{~mL})$ to give the objective polymer (4) in $70 \%$ yield. ${ }^{1} \mathrm{H} \mathrm{NMR}\left(\mathrm{CDCl}_{3}, 400 \mathrm{MHz}, \delta, \mathrm{ppm}\right): 0.75-1.40,1.83-$ 1.97 (aliphatic $H), 2.92-3.67\left(\mathrm{Ar}-\mathrm{OCH}_{3}\right), 3.67-4.01$ ( $\mathrm{Ar}-$ $\left.\mathrm{CH}_{2}-\mathrm{Ar}\right), \quad 4.18-4.32 \quad\left(\mathrm{C}=\mathrm{N}-\mathrm{CH}_{2}\right), \quad 5.96-6.32 \quad(\mathrm{Ar}-\mathrm{H})$, 8.15-8.30 (Ar-CH=N-); FT-IR $\left(\mathrm{KBr}, \mathrm{cm}^{-1}\right)$ : 2937, 2833 $\left(-\mathrm{CH}_{2}-\right), 1647(\mathrm{C}=\mathrm{N}), 1602$ (aromatic $\left.\mathrm{C}=\mathrm{C}\right), 1106(\mathrm{Ar}-\mathrm{O}-$ $\mathrm{CH}_{3}$ ).

Cure Reaction by Means of Diamine. $3(0.15 \mathrm{~g}, 0.18 \mathrm{mmol}$ as an aldehyde unit), 1,5-diaminopentane $(0.0030 \mathrm{~g}, 0.030 \mathrm{mmol})$ solution of ethanol $(5 \mathrm{~mL})$ were added to a $20 \mathrm{~mL}$ roundbottom flask. The mixture was stirred at $40{ }^{\circ} \mathrm{C}$ for $10 \mathrm{~min}$ to give the insoluble gel (5) in $86 \%$ yield. FT-IR $\left(\mathrm{KBr}, \mathrm{cm}^{-1}\right)$ : 2933, $2832\left(-\mathrm{CH}_{2}-\right), 1638(\mathrm{C}=\mathrm{N}), 1597$ (aromatic $\left.\mathrm{C}=\mathrm{C}\right), 1105$ $\left(\mathrm{Ar}-\mathrm{OCH}_{3}\right)$.

Hydrolysis of 5. To a $20 \mathrm{~mL}$ round-bottom flask was added 5 $(0.1 \mathrm{~g}), \mathrm{THF}(5 \mathrm{~mL})$ and $1 \mathrm{~N} \mathrm{HCl}$ aq. $(1 \mathrm{~mL})$. After stirring at room temperature for $2 \mathrm{~d}$, the mixture was poured into methanol $(50 \mathrm{~mL})$ to give the product $(6)$ in $>99 \%$ yield. ${ }^{1} \mathrm{H}$ NMR $\left(\mathrm{CDCl}_{3}, 400 \mathrm{MHz}, \delta, \mathrm{ppm}\right): 2.95-3.79\left(\mathrm{Ar}-\mathrm{OCH}_{3}\right)$, 3.79-4.09 (Ar-CH $\left.\mathrm{CH}_{2}-\mathrm{Ar}\right)$, 5.92-6.26 (Ar-H), 10.13-10.29 (Ar$\mathrm{CHO})$.

\section{RESULTS AND DISCUSSION}

\section{Polymerizability of 1}

We attempted to prepare a novel reactive novolac. First, the addition-condensation of $\mathbf{1}$ with formaldehyde was carried out according to the procedure described in the experimental section; however, no polymer was obtained. When this polymerization, catalyzed by $12 \mathrm{~mol} / \mathrm{L} \mathrm{HCl}$ aq., was carried out at $120^{\circ} \mathrm{C}$ in an acetic acid solution, a crude product was obtained in $52 \%$ yield. After the application of high-pressure liquid chromatography (HPLC), the required product was obtained from the monomers in $10 \%$ yield. The numberaverage molecular weight $\left(M_{\mathrm{n}}\right)$ and the polydispersity index $\left(M_{\mathrm{w}} / M_{\mathrm{n}}\right)$ of the obtained product were 3100 and 1.4 , respectively. No peaks of formyl groups were detected in the ${ }^{1} \mathrm{H}$ NMR and FT-IR spectra of the product. The absence of peaks indicates that the addition-condensation reaction via the formyl groups of the substrate also occurred during the polymerization; the polymer backbone of the product obtained thus appeared to have a branched structure.

\section{Reactive Trimethoxybenzene Novolac (3)}

It was difficult to polymerize $\mathbf{1}$ with formaldehyde without side reactions. To promote the polymerization of $\mathbf{1}$ with formaldehyde and suppress the side reactions of the formyl groups, $\mathbf{2}$ was used as a comonomer in the polymerization. The nucleophilicity of $\mathbf{2}$ is sufficient for a rapid nucleophilic attack (addition reaction) on the carbocation to form a methylol group. This substrate can react with either $\mathbf{1}$ or $\mathbf{2}$ (condensation reaction); therefore, if these addition-condensation reactions proceeded continuously, a random terpolymer would be formed. Furthermore, adding $\mathbf{2}$ as a comonomer appears to decrease the content of the formyl groups in the polymer backbone; furthermore, the side reactions may be suppressed. The polymerization of $\mathbf{1}, \mathbf{2}$, and formaldehyde was carried out according to the procedure described in the experimental section (Scheme 1). The polymerization proceeded homogeneously, and organo-soluble polymer $\mathbf{3}$ was obtained as a pale blue precipitate in $9 \%$ yield. The FT-IR spectrum of $\mathbf{3}$ indicates that $\mathbf{3}$ has an alkyl unit, a carbonyl group, an aromatic ring, and an ether unit (Figure 1(a)). In the ${ }^{1} \mathrm{H}$ NMR spectrum of $\mathbf{3}$, peaks are observed at 2.95-3.80 ppm (methoxy protons), 3.80$4.40 \mathrm{ppm}$ (methylene protons), 5.90-6.25 ppm (aromatic protons), and 10.14-10.30 ppm (formyl protons) (Figure 2). The ${ }^{13} \mathrm{C} \mathrm{NMR}$ spectrum of 3 shows peaks at $17.0-21.0 \mathrm{ppm}$ 


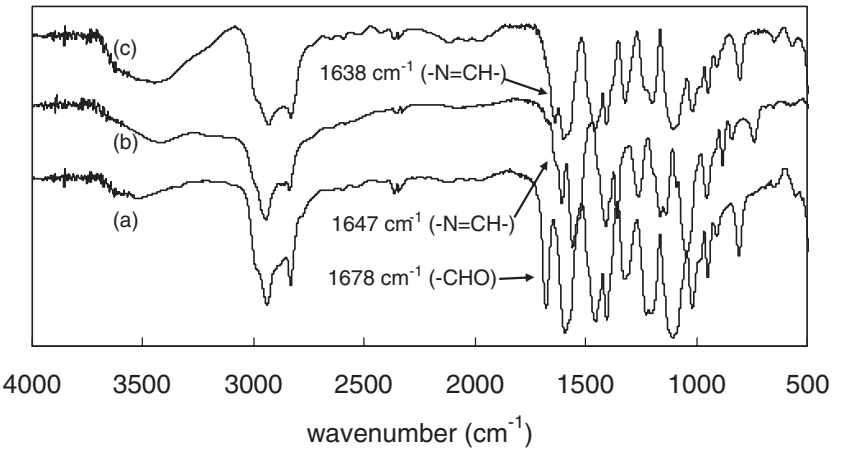

Figure 1. FT-IR spectra of polymer 3 (a), 4 (b) and 5 (c).

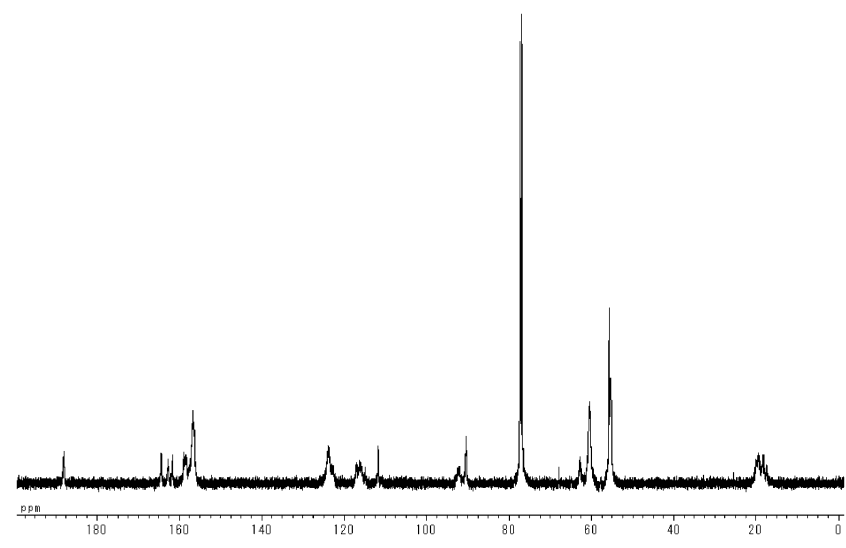

Figure 3. ${ }^{13} \mathrm{C}$ NMR spectrum in $\mathrm{CDCl}_{3}$ of polymer 3.

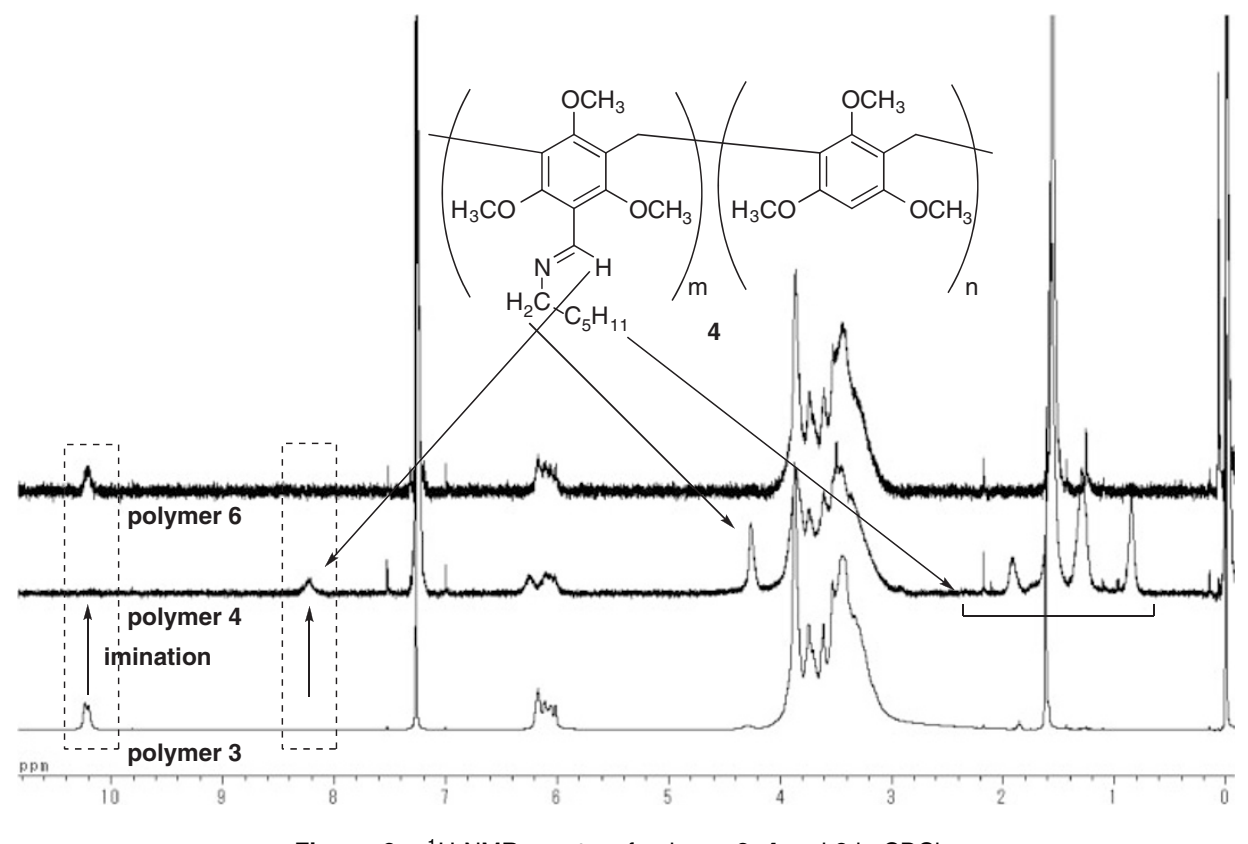

Figure 2. ${ }^{1} \mathrm{H}$ NMR spectra of polymer 3,4 and 6 in $\mathrm{CDCl}_{3}$.

(methylene carbons), 54.0-64.0 ppm (methoxy carbons), 90.0$94.0 \mathrm{ppm}$ (nonsubstituted aromatic carbons), 114.0-118.0 and $122.0-126.0 \mathrm{ppm}$ (aromatic carbons attached to methylene units), 155.0-160.0 and 161.0-165.0 ppm (aromatic carbons attached to methoxy groups), and $187.0-189.0 \mathrm{ppm}$ (formyl carbons) (Figure 3 ). These results indicate that the polymer backbone of $\mathbf{3}$ consists of substituted phenylene and methylene units. Furthermore, it is possible to calculate the degree of the branching points, and the abundance ratio of each unit, using the integral ratio of the formyl, aromatic, and methylene/ methoxy protons from the ${ }^{1} \mathrm{H}$ NMR spectrum of $\mathbf{3}$. However, the methine proton, obtained from the reaction between the formyl groups and the substrate, has not been detected at 5.0$5.5 \mathrm{ppm}$, indicating that branching moieties from the formyl groups were not formed. In contrast, the integral ratio of each unit $(\mathbf{1}: 2=1.0: 2.7)$ approximately corresponds to the calculated value, indicating that the reactivity of $\mathbf{2}$ was higher than that of $\mathbf{1}$ because $\mathbf{2}$ was richer in electron density than $\mathbf{1}$. That is, the addition-condensation of $\mathbf{1}$ and $\mathbf{2}$ with formaldehyde successfully afforded formyl group-containing novolacs without side reactions. Furthermore, the content of the formyl groups was estimated to be $26 \%$. From gel permeation chromatography (GPC), the $M_{\mathrm{n}}$ and $M_{\mathrm{w}} / M_{\mathrm{n}}$ of $\mathbf{3}$ were found to be 4200 and 1.2 respectively. The yield of $\mathbf{3}$ was very low (9\%), which probably resulted from the inclusion of oligomers mainly with low molecular weights in the obtained product. When this polymerization was carried out according to Scheme 1, without purification, product $\mathbf{3}^{\prime}$ was obtained as a viscous liquid. The GPC of polymers $\mathbf{3}$ and $\mathbf{3}^{\prime}$ was performed to examine the content of polymers with high-molecular-weight fractions (Figure 4). The main unimodal peak of $\mathbf{3}$ (bold line) appears at $9.5 \mathrm{~min}$. However, the chart of $\mathbf{3}^{\prime}$ (Figure 4, solid line), which is the crude product without purification, shows multimodal fractions around the low-molecular-weight regions. These results indicate that the polymer obtained by the addition-condensation of $\mathbf{1}$ and $\mathbf{2}$ with formaldehyde mainly 


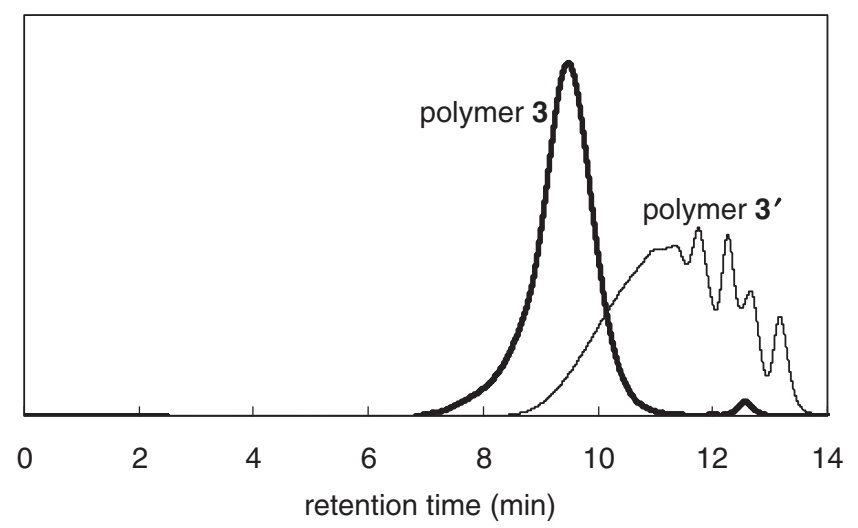

Figure 4. GPC charts of polymer 3 (bold line) and $\mathbf{3}^{\prime}$ (solid line) (eluent: THF).

consists of oligomers with low molecular weights and includes a small amount of high-molecular-weight polymers.

Under the same reaction conditions, the addition-condensation of 1 with formaldehyde did not proceed; however, the polymerization of $\mathbf{1}, \mathbf{2}$ and formaldehyde successfully yielded the reactive polymer. On the basis of these results, the reactivity of the substrates and the mechanism of the addition-condensation of $\mathbf{1}$ and $\mathbf{2}$ with formaldehyde can be discussed (Scheme 2). In general, the reaction rate of the addition reaction of the aromatic substrate with the carbocation from formaldehyde is considerably slower than that of the condensation reaction in acid-catalyzed addition-condensation, that is, the addition reaction can be regarded as a ratedetermining step. ${ }^{1}$ From the result of the polymerization of $\mathbf{1}$ and formaldehyde, it is clear that the addition reaction between the aromatic substrate and the carbocation barely proceeds. On the other hand, the addition-condensation of $\mathbf{2}$ with formaldehyde can proceed under the reaction conditions of Scheme 1. That is, during the addition-condensation of $\mathbf{1}$ and 2 with formaldehyde, the strong nucleophilic substrate, 2 , initially attacks a carbocation from formaldehyde, and a methylol (hydroxymethyl) group is formed on the benzene ring. After a proton cation gets attached to the oxygen of a methylol group (intermediate formation), 1 or $\mathbf{2}$ attacks the carbon of the protonated methylol group to release water. Polymerization proceeds when these reactions are repeated, i.e., the polymerization of $\mathbf{1}$ with formaldehyde can proceed only in the presence of $\mathbf{2}$; and then, the product appears to form a random copolymer from the methylene units without any adjacent trimethoxybenzaldehydes in the polymer backbone.

The addition-condensation of $o$-anisaldehyde with formaldehyde was also performed under the same reaction conditions of Scheme 1 to confirm the permanence of the formyl group during polymerization. However, the ${ }^{1} \mathrm{H}$ NMR spectrum of the obtained product showed no peaks derived from formyl protons. This indicates that two methoxy groups at the $o$-positions can function as protecting groups for formyl groups; furthermore, there is a possibility that the reactivity of<smiles>COc1cc(OC)c(OC)c(OC)c1</smiles><smiles>C#CCOc1ccc(OC)c(OC)c1</smiles>

Scheme 2. Prospective mechanism in the addition-condensation of $\mathbf{1}$ and $\mathbf{2}$ with formaldehyde. 


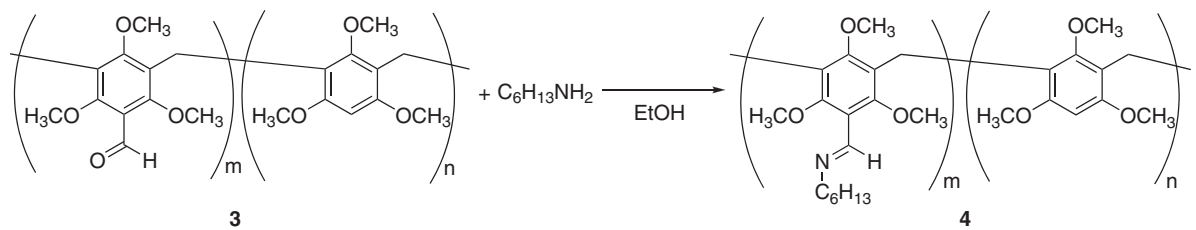

Scheme 3. Polymer reaction of $\mathbf{3}$ with hexylamine.
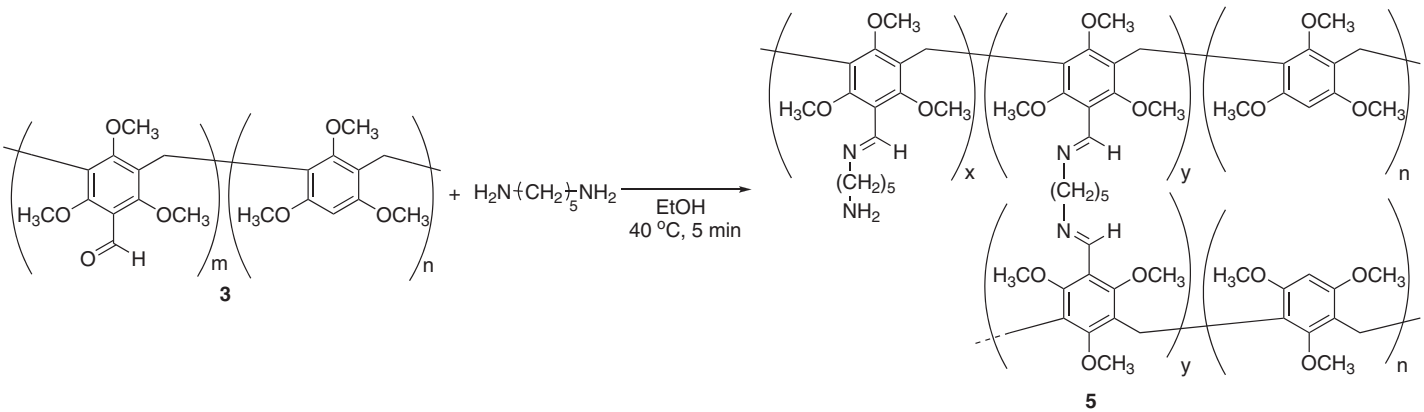

Scheme 4. Crosslinking reaction of 3 with 1,5-diaminopentane.

the formyl carbon of $\mathbf{1}$ is lower than that of $o$-anisaldehyde because $\mathbf{1}$ has a lot of methoxy groups on the benzene ring, which act as electron-donating groups.

\section{Polymer Reactions and Cure}

To investigate the potential of $\mathbf{3}$ as a reactive polymer, polymer reactions were carried out via imination with mono- or diamine. The imination of $\mathbf{3}$ with hexylamine was carried out to evaluate the reactivity of the formyl groups of $\mathbf{3}$ (Scheme 3 ). The obtained polymer, $\mathbf{4}$, was soluble in THF and chloroform. The FT-IR spectrum of $\mathbf{4}$ showed strong absorption at $1647 \mathrm{~cm}^{-1}$, which is a characteristic of $\mathrm{C}=\mathrm{N}$ stretching in imino groups (Figure 1(b)). The presence of hexyl proton peaks $(0.75-1.40,1.83-1.97$, and $4.18-4.32 \mathrm{ppm})$ and an imino proton $(8.15-8.30 \mathrm{ppm})$ in the ${ }^{1} \mathrm{H}$ NMR spectrum of 4 (Figure 2) was confirmed; however, the peaks derived from formyl protons disappeared. The imination of formyl groups with hexylamine proceeded completely, indicating that $\mathbf{3}$ can be applied as a reactive novolac.

If diamine was used as an imination reagent, the obtained product exhibited a network structure due to the cross linking of 3 with imine bond formations. The polymer reaction of 3 with 1,5-diaminopentane was carried out to realize the imination of formyl groups (Scheme 4). After the imination of 3, a yellow gel (5) was obtained in $89 \%$ yield. In the FT-IR spectrum of 5 (Figure 1(c)), the peak of the formyl groups disappeared, and that of the imino group was confirmed at $1638 \mathrm{~cm}^{-1}$. This indicates that the imination of 3 does occur, and $\mathbf{3}$ can form a gel conformation via imination with diamine. Moreover, when the hydrolysis reaction of $\mathbf{5}$ was carried out in a $1 \mathrm{~N} \mathrm{HCl}$ aq./THF solution at room temperature, the obtained product (6) had the formyl groups of $\mathbf{3}$, which were detected from the ${ }^{1} \mathrm{H}$ NMR spectrum of 6 (Figure 2). This indicates that 3 can be used as a recyclable polymer. ${ }^{15}$

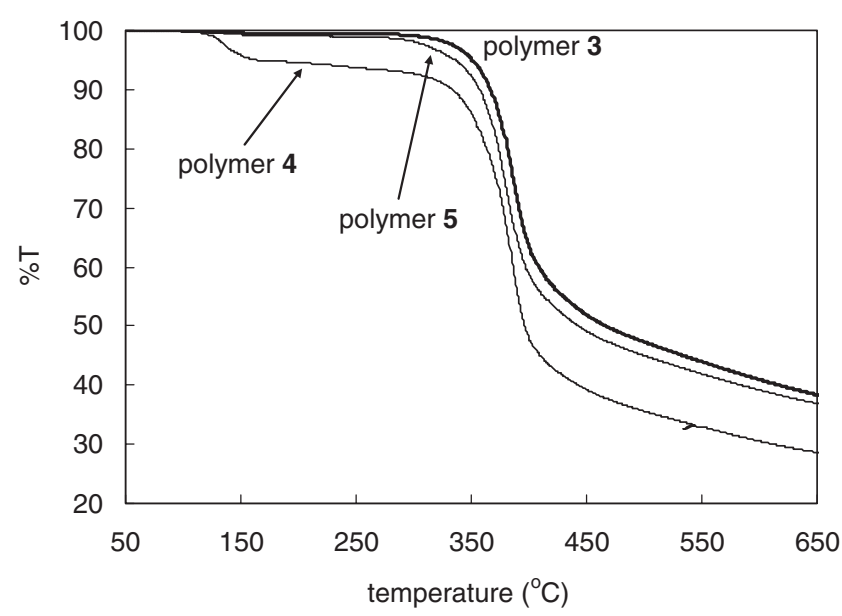

Figure 5. Thermogravimetric analyses of polymer 3-5 in $\mathrm{N}_{2}$ flow.

\section{Thermal Properties}

The thermal properties of the obtained polymers (3-5) were examined by TGA under a nitrogen atmosphere (Figure 5). All samples were annealed at $100{ }^{\circ} \mathrm{C}$ for $10 \mathrm{~min}$ for complete drying. The temperature at $5 \%$ loss in weight $\left(T_{\mathrm{d} 5}\right)$ of $\mathbf{3}$ was $351{ }^{\circ} \mathrm{C}$. As compared to $\mathbf{3}$, the imino group-containing polymer, 4, derived from $\mathbf{3}$ and monoamine, shows remarkably low thermal stability $\left(T_{\mathrm{d} 5}=163^{\circ} \mathrm{C}\right)$. This property probably stems from the degradation of the imino groups on the side chains. In the case of $\mathbf{5}$ obtained from $\mathbf{3}$ and diamine, the $T_{\mathrm{d} 5}$ value decreases slightly $\left(335^{\circ} \mathrm{C}\right)$ compared to that of $\mathbf{3}$. As a result, $\mathbf{5}$ shows sufficient thermal stability despite the presence of many imino groups and alkyl chains in the polymer. This indicates that the mobility of the polymer backbones is fixed due to crosslinking with diamine; consequently, the imino groups appear to be protected by the network structures of $\mathbf{5}$. 


\section{CONCLUSION}

We successfully prepared a reactive alkoxylated novolac having formyl groups (3) by acid-catalyzed addition-condensation of 2,4,6-trimethoxybenzaldehyde (1) and 1,3,5-trimethoxybenzene (2) with formaldehyde. During this polymerization, no side reactions occurred at the formyl groups of $\mathbf{1}$. Furthermore, the imination of $\mathbf{3}$ with mono- and diamine was carried out to evalute the potential of $\mathbf{3}$ for use as a reactive polymer. For the imination of $\mathbf{3}$, each polymer reaction efficiently proceeded. Therefore, a novel curing system can be realized by using a diamine, and $\mathbf{3}$ can serve as an aromatic reactive polymer which can be used as a curing agent (a polymer additive used to improve the thermal properties of commodity polymers). The synthesis of a reactive trimethoxybenzene novolac having acetyl groups and their polymer reaction with a Grignard reagent are described in a separate paper. $^{16}$

Acknowledgment. This work was partially supported by SORST program from JST and Industrial Technology Research \& Development Grant (04A23030) from NEDO of JAPAN.

Received: December 10, 2008 Accepted: January 27, 2009 Published: March 11, 2009

\section{REFERENCES}

1. a) A. Knop and L. A. Pilato, "Phenolic Resins," Springer-verlag, Berlin, 1985. b) G. Konishi, J. Syn. Org. Chem. Jpn., 66, 705 (2008).

2. a) T. Takeichi, T. Kawauchi, and T. Agag, Polym. J., 40, 1121 (2008). b) J. Cui, Y. Yan, J. Liu, and Q. Wu, Polym. J., 40, 1067 (2008). c) B. S. Kaith and S. Kalia, Polym. J., 39, 1319 (2007). d) G. Pan, Z. Du, C. Zhang, C. Li, X. Yang, and H. Li, Polym. J., 39, 478 (2007).

e) K. Suzuki, H. Matsumoto, M. Minagawa, M. Kimura, and A. Tanioka, Polym. J., 39, 1128 (2007).

f) T. Nemoto, I. Amir, and G. Konishi, Polym. J., 41, 338 (2009). g) M. Ukaji, M. Takamura, K. Shirai, W. Gang, T. Yamauchi, and N. Tsubokawa, Polym. J., 40, 607 (2008).

3. F. Helfferich, "Ion Exchange," NewYork, McGraw Hill, 1962.

4. a) J. Kadota, T. Fukuoka, H. Uyama, K. Hasegawa, and S. Kobayashi, Macromol. Rapid Commun., 25, 441 (2004). b) H. C. Y. Koh, J. Dai, E. Tan, and W. Liang, J. Appl. Polym. Sci., 101, 1775 (2006).

5. B. A. Adams and E. L. Holmes, J. Soc. Chem. Ind., 54, 1 (1935).

6. a) J. M. J. Fréchet, G. D. Darling, S. Itsuno, P. Z. Lu, M. V. de Meftahi, and W. A. Rolls, Pure Appl. Chem., 60, 353 (1988).

b) N. N. Ghosh, B. Kiskan, and Y. Yagci, Prog. Polym. Sci., 32, 1344 (2007).

7. a) H. Ritter and R. Sperber, Macromolecules, 27, 5919 (1994).

b) T. F. Scott, A. D. Schneider, W. D. Cook, and C. N. Bowman, Science, 308, 1615 (2005).

c) M. A. Tasdelen, V. Kumbaraci, N. Talinli, and Y. Yagci, Macromolecules, 40, 4406 (2007).

d) S. Sugawara, M. Tomoi, and T. Oyama, Polym. J., 39, 129 (2007).

e) K. Tsuchiya, Y. Shibasaki, and M. Ueda, Polym. J., 39, 442 (2007).

f) T. Nishikubo, H. Kudo, and H. Nomura, Polym. J., 40, 310 (2008).

g) K. Mizoguchi and M. Ueda, Polym. J., 40, 645 (2008).

h) N. Matsumi and Y. Chujo, Polym. J., 40, 77 (2008).

8. R. B. Merrifield, J. Am. Chem. Soc., 85, 2149 (1963).

9. a) P. Hodge, Chem. Soc. Rev., 26, 417 (1997).

b) B. Yan and H. C. Gremlich, J. Chromatogr., B: Biomed. Sci. Appl., 725, 91 (1999).

10. V. Strehmel, B. Strehmel, F. Karl, G. Muller, and M. Fedtke, Angew. Makromol. Chem., 200, 125 (1992).

11. D.-M. Shin, N. Ozeki, Y. Nakamoto, and G. Konishi, Macromol. Res., 14, 255 (2006).

12. a) T. Kimura, Y. Nakamoto, and G. Konishi, Polym. J., 38, 606 (2006).

b) T. Nemoto, T. Ueno, M. Nishi, D.-M. Shin, Y. Nakamoto, and G. Konishi, Polym. J., 38, 1278 (2006).

c) J. Jeerupan, G. Konishi, T. Nemoto, D. M. Shin, and Y. Nakamoto, Polym. J., 39, 762 (2007).

d) A. Kobayashi and G. Konishi, Polym. J., 40, 590 (2008).

e) T. Nemoto and G. Konishi, Polym. J., 40, 651 (2008).

f) T. Nemoto, G. Konishi, T. Arai, and T. Takata, Polym. J., 40, 622 (2008).

13. a) N. Sreenivasachary and J. M. Lehn, Proc. Natl. Acad. Sci. U.S.A., 102, 5938 (2005).

b) T. Takata and H. Otsuka, J. Syn. Org. Chem. Jpn., 64, 194 (2006).

14. L. Piazzi, F. Belluti, A. Bisi, S. Gobbi, S. Rizzo, M. Bartolini, V. Andrisano, M. Recanatini, and A. Rampa, Bioorg. Med. Chem., 15, 575 (2007).

15. a) Y. Chujo, K. Sada, and T. Saegusa, Macromolecules, 23, 2636 (1990).

b) Y. Chujo, K. Sada, and T. Saegusa, Macromolecules, 26, 6315 (1993).

c) Y. Chujo, K. Sada, and T. Saegusa, Macromolecules, 26, 6320 (1993).

d) P. Cordier, F. Tournilhac, C. Soulie-Ziakovic, and L. Leibler, Nature (London), 451, 977 (2008).

16. T. Nemoto, I. Amir, and G. Konishi, Polym. J., 41, 395 (2009). 